\title{
Synthesis of folate- pegylated polyester nanoparticles encapsulating ixabepilone for targeting folate receptor overexpressing breast cancer cells
}

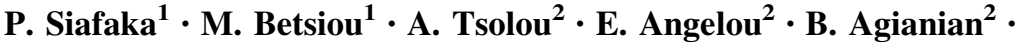

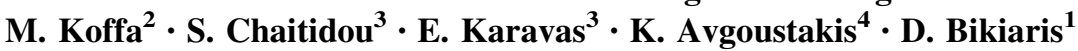

Received: 21 April 2015/ Accepted: 24 October 2015/Published online: 5 November 2015

(C) Springer Science+Business Media New York 2015

\begin{abstract}
The aim of this study was the preparation of novel polyester nanoparticles based on folic acid (FA)functionalized poly(ethylene glycol)-poly(propylene succinate) (PEG-PPSu) copolymer and loaded with the new anticancer drug ixabepilone (IXA). These nanoparticles may serve as a more selective (targeted) treatment of breast cancer tumors overexpressing the folate receptor. The synthesized materials were characterized by ${ }^{1} \mathrm{H}-\mathrm{NMR}$, FTIR, XRD and DSC. The nanoparticles were prepared by a double emulsification and solvent evaporation method and characterized with regard to their morphology by scanning electron microscopy, drug loading with HPLCUV and size by dynamic light scattering. An average size of $195 \mathrm{~nm}$ and satisfactory drug loading efficiency (3.5\%) were observed. XRD data indicated that IXA was incorporated into nanoparticles in amorphous form. The nanoparticles exhibited sustained drug release properties in vitro. Based on in vitro cytotoxicity studies, the blank FA-PEG-PPSu nanoparticles were found to be non-toxic to the cells. Fluorescent nanoparticles were prepared by conjugating Rhodanine B to PEG-PPSu, and live cell, fluorescence, confocal microscopy was applied in order to demonstrate the ability of FA-PEG-PPSu nanoparticles to
\end{abstract}

D. Bikiaris

dbic@chem.auth.gr

1 Department of Chemistry, Aristotle University of Thessaloniki, 54124 Thessaloniki, Macedonia, Greece

2 Department of Molecular Biology and Genetics, Democritus University of Thrace, Xanthi, Greece

3 Pharmathen S.A, Pharmaceutical Industry, Dervenakion Str6, 15351 Attiki, Greece

4 Department of Pharmacy, University of Patras, 26500 Patras, Greece enter into human breast cancer cells expressing the folate receptor.

Graphical Abstract

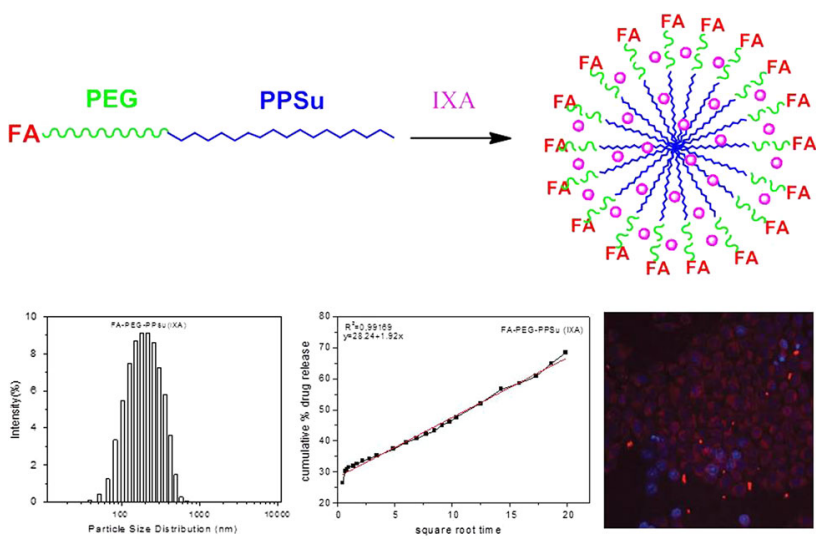

\section{Introduction}

Breast cancer accounts for $22.9 \%$ of all cancers (excluding non-melanoma skin cancers) in women. Although breast cancer is less common between men, men tend to have poorer outcomes due to delays in diagnosis [1]. It is estimated that 1.1 million new cases appear annually, and about 400.000 related deaths are reported worldwide [2]. A new effective anticancer drug in the breast cancer treatment is ixabepilone (IXA), which is the first of a new class of microtubule-targeting agents called epothilones. It is a semisynthetic analogue of natural epothilone B that was rationally designed to have improved metabolic stability compared with natural epothilone B. In addition to its favorable pharmacokinetics and metabolic stability, IXA 
displays reduced susceptibility to multidrug-resistancemediated efflux and has demonstrated preclinical antitumor activity in a number of in vivo models of tumors that are resistant through overexpression of multidrug-resistance proteins and to taxanes [3, 4].

A major challenge in cancer therapy is the selective (targeted) delivery of anticancer drugs to the tumor cells, which would reduce drug toxicity to normal tissues and cells. While systemic drug delivery already hinges largely on physicochemical properties of the drug, such as size, diffusivity, and plasma protein binding affinity, tumors possess a dense, heterogeneous vasculature and an outward net convective flow that act as hurdles to efficient drug deposition at the target site. Nanocarrier mediated delivery has emerged as a successful strategy to enhance delivery of therapeutics and imaging agents to tumors, thereby increasing the potential for diagnosis at an earlier stage or for therapeutic success (or both). Drug incorporation into nanoparticulate carriers could provide for a more selective drug delivery (drug targeting), prolong the biological activity, protect drug against degradation, and could control the rate of drug release allowing for the reduction of drug administration frequency [5].

Biocompatible and biodegradable polymers, such as poly(lactic acid) (PLA), its copolymers with glycolic acid (PLGA) and poly( $\varepsilon$-caprolactone) (PCL), have been extensively used to produce nanoparticles for controlled release and drug targeting applications. Although these polyesters are widely used as drug carriers and implants, their low degradation rate [6] sparked an increased interest for the synthesis of new materials with innovative and enhanced properties. Poly(propylene succinate) (PPSu) is such a new biocompatible polyester with relatively high biodegradation rate due to its low degree of crystallinity [7, 8]. Furthermore, due to its low melting point $\left(\mathrm{T}_{\mathrm{m}}=44{ }^{\circ} \mathrm{C}\right)$, which is close to the physiological body temperature $[9,10]$, PPSu could be used as drug nanocarrier appropriate for selective drug release at the tumor site using local hyperthermia. In order to avoid the rapid removal of these nanoparticles from systemic circulation after intravenous administration, due to rapid uptake by reticular endothelial system (RES), pegylated PPSu nanoparticles based on PEG-PPSu copolymers have been developed [11-18]. Although pegylation of nanoparticles surface can lead to their preferential accumulation in tumor tissue due to the enhanced permeability and retention (EPR) phenomenon, it does not appear to increase the uptake of nanoparticles, and consequently of their drug load, by cancer cells [19]. In order to enhance nanoparticles uptake by tumor cells, targeting moieties, e.g. antibodies or antibody fragments, peptides and sugars, specifically recognized by receptors in cancer cells are attached on nanoparticles [20].
The aim of the present study is to synthesize targetable PEG-PPSu nanoparticles of ixabepilone by attaching folic acid (FA) on PEG-PPSu copolymers. FA can be conjugated to polymers after modification by an appropriate "spacer" (i.e. $-\mathrm{NH}_{2}-\mathrm{CH}_{2}-\mathrm{CH}_{2}-\mathrm{SH}-$ ) that maintain its activity and functionality $[5,18,21]$. The ixabepilone-loaded FA-PEG-PPSu nanoparticles were prepared by a modified w/o/w emulsification and solvent evaporation process and characterized for their physicochemical and drug release properties. Furthermore, and in order to study the uptake of these nanoparticles by cancer cells using live cell fluorescence microscopy, fluorescent Rhodamine was covalently attached to PEG-PPSu used to prepare the nanoparticles.

\section{Materials and methods}

\subsection{Materials}

For the synthesis of conjugated polyester succinic acid (purum $99 \%$ ), 1,3-propanediol (purum $99 \%$ ), tetrabutyl titanate (TBT), tripolyphenylphosphine $\left(\mathrm{Ph}_{3} \mathrm{P}\right)$, diethyl azodicarboxylate (DEAD), poly(ethylene glycol) (PEG) with molecular weight 2000, maleimide (MAL) and $\mathrm{Sn}$ (octanoate) were use purchased from Aldrich Chemical Co. N-hydroxysuccinimide (NHS), triethylamine (TEA) and dicyclohexylcarbodiimide (DCC) were also purchased from Aldrich Chemical Co. Ixabepilone drug was purchased from BOC Sciences. All the other reagents were of analytical grade.

\subsection{Synthesis of functional polyesters}

\subsubsection{Functionalization of PEG with maleimide (MAL- $P E G)$ and conjugation of MAL-PEG into PPSu (MAL-PEG-PPSu) (Scheme 1)}

For the preparation of MAL-PEG a $250 \mathrm{~mL}$ round bottom flask was charged with $\mathrm{Ph}_{3} \mathrm{P}(2.70 \mathrm{~g}, 10.3 \mathrm{mmol})$ to which $70 \mathrm{~mL}$ of THF were added. The resulting clear solution was cooled to $-78{ }^{\circ} \mathrm{C}$. DEAD $(1.63 \mathrm{~mL}, 10.3 \mathrm{mmol})$ was added over 2-3 min. The yellow reaction mixture was stirred $5 \mathrm{~min}$ and then PEG $(1.36 \mathrm{~mL}, 11.3 \mathrm{mmol})$ was added over $1 \mathrm{~min}$ and stirred for $5 \mathrm{~min}$. Neopentyl alcohol $(0.50 \mathrm{~g}, 5.7 \mathrm{mmol})$ and MAL $(1.00 \mathrm{~g}, 10.3 \mathrm{mmol})$ were added sequentially to the reaction mixture as solids. The resulting suspension was allowed to remain at $-78{ }^{\circ} \mathrm{C}$ for 5 min during which time most of the MAL dissolved. The cooling bath was then removed, and the reaction was stirred overnight at ambient temperature. Thin layer chromatography (TLC) indicated complete consumption of MAL. The clear solution was concentrated to 
Scheme 1 Schematic representation of functionalization of PEG with Maleimide (MAL-PEG) and synthesis of MAL-PEG-PPSu during reaction of MAL-PEG with PPSu polyester

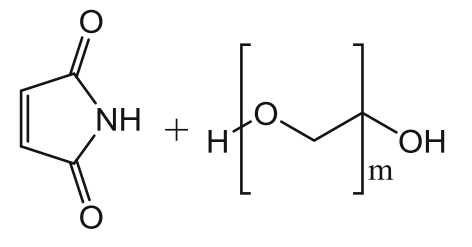<smiles>CC1=CC(=O)N(CCC(C)(O)c2ccccc2)C1=O</smiles><smiles>CC(O)CCCC(C)N1C(=O)C=CC1=O</smiles>

$+$<smiles>CC(C)OCCCOC(=O)CCC(=O)C(C)(C)O</smiles>
MAL-PEG Toluene, $5 \mathrm{~h}\rfloor \mathrm{Sn}(\mathrm{Oct})_{2}$

PPSu

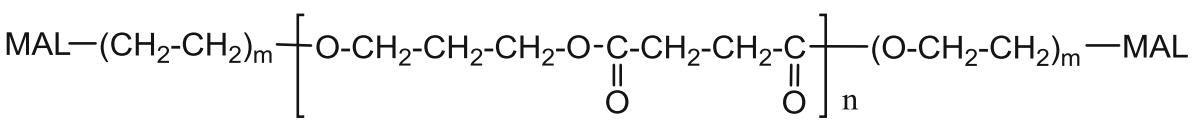

MAL-PEG-PPSU approximately $1 / 4$ of the original volume under vacuum and then it was applied to a silica gel column ( 2 in $\times 8$ in) and eluted with 5:1 hexanol/EtOAc to obtain MAL-PEG (Scheme 1), after removing solvent.

For the preparation of MAL-PEG-PPSu the synthesis of PPSu was performed following a two stage melt polycondensation method (esterification and polycondensation) in a glass batch reactor according to the method described in our previous study [5].

A pre-determined amount of MAL-PEG-OH, PPSu and $\mathrm{Sn}(\mathrm{Oct})_{2}$ catalyst $(0.1 \%$ amount of polyester in molar ratio) was dissolved in dry toluene in a flame-dried twoneck flask equipped with a distillation set. The mixture was heated to $130{ }^{\circ} \mathrm{C}$ and refluxed for $5 \mathrm{~h}$. Subsequently, the solution was cooled to room temperature and precipitated into cold diethyl ether. The product (MAL-PEG-PPSu) (Scheme 1) was collected by filtration and dried in vacuum at room temperature.

\subsubsection{Conjugation of folic acid onto MAL-PEG-PPSu (FA-PEG-PPSu) (Scheme 2)}

For the synthesis of FA-PEG-PPSu, the folic acid should first be activated as folate-NHS ester (Scheme 2a). The carboxylate group of FA was activated by N-hydroxysuccinimide (NHS) and dicyclohexylcarbodiimide (DCC). Briefly, $1 \mathrm{~g}$ FA was dissolved in $50 \mathrm{~mL}$ dimethyl sulfoxide (DMSO). Then, NHS and DCC in a stoichiometric ratio of FA: NHS: DCC 1:2:1 were added to the solution. The solution was stirred $16 \mathrm{~h}$ at room temperature under shielding from light. The by-product dicyclohexylurea was removed by filtration. The supernatant was added in glacial diethylether and the solid formed was filtrated and dried for 3 days at $30{ }^{\circ} \mathrm{C}$. The dried product was dissolved in DMSO and cysteamine- hydrocloride and $0.1 \mathrm{~mL}$ (TEA) were added. Subsequently, the solution was stirred for $24 \mathrm{~h}$ and the final product was recovered after pouring into diethylether. The modified-folic acid (FA-NHS) was washed thrice with purified water and dried at $30{ }^{\circ} \mathrm{C}$.

In the second step (Scheme $2 b$ ), activated FA reacted with MAL-PEG-PPSu. Briefly, $10 \mathrm{mg}$ of FA-NHS were added in $20 \mu \mathrm{L}$ of TEA and a proper amount of MALPEG-PPSu was dissolved in $10 \mathrm{~mL}$ of DMSO. The solutions were mixed and stirred for $24 \mathrm{~h}$ at room temperature. DMSO residue was removed via distillation in order to receive a yellow colored polymer.

\subsubsection{Conjugation of Rhodamine B to PEG-PPSu (Scheme 3a, b)}

In order to be able to observe the entry of the nanoparticles into cancer cells with fluorescence microscopy, functionalized with the fluorescent dye Rhodamine B (Rh) PEG-PPSu was synthesized, which was then used to prepare fluorescent nanoparticles. The $\mathrm{Rh}$ conjugated PEG-PPSu was synthesized according to a published work [22]. Briefly, activation of $\mathrm{Rh}$ was effected when $0.1 \mathrm{gr}$ of $\mathrm{Rh}$ was added into $10 \mathrm{~mL}$ DMSO and $0.06 \mathrm{~mL}$ TEA. After dissolving the dye, $51.6 \mathrm{mg}$ of DCC and NHS were added. Magnetic stirring in the dark was continued for $24 \mathrm{~h}$ and the dicyclohexylurea produced was removed by filtration. DMSO and TEA were evaporated under 
Scheme 2 a Schematic diagram of a production of activated folic acid (NHS-ester of FA) and $\mathbf{b}$ folic acid conjugation on PEG-PPSu to obtain FA-PEG-PPSu (a)<smiles>Nc1nc(O)c2nc(CNc3ccc(C(=O)NC(=O)O)cc3)cnc2n1</smiles><smiles>OC(Cl)(Cl)C(Cl)(Cl)Cl</smiles><smiles>NC1=NC(O)C2N=C(CNc3ccc(C(=O)NC(CO)C(=O)OC4C(=O)CCC4=O)cc3)C=NC2=N1</smiles>

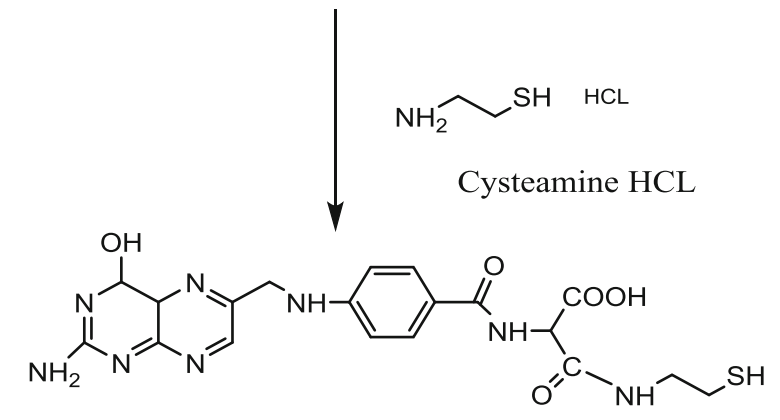

Activated NHS-Ester of FA

(b)<smiles>CC(C)OCCCCOC(=O)CCC(=O)C(C)(C)C(=O)OCCCOCc1ccccc1</smiles><smiles>CCCC(=O)NC(O)c1ccc(Nc2cnc3nc(N)nc(O)c3n2)cc1</smiles>
Folate-HS- $\left.\left[\mathrm{O}-\mathrm{CH}_{2}-\mathrm{CH}_{2}-\mathrm{CH}_{2}-\mathrm{O}-\mathrm{C}_{\mathrm{O}}-\mathrm{CH}_{2}-\mathrm{CH}_{2}-\mathrm{C}\right]\right]_{\mathrm{n}}\left[\mathrm{O}-\mathrm{CH}_{2}-\mathrm{CH}_{2}-\mathrm{O}\right]_{\mathrm{m}}$ SH-Folate vacuum and the activated Rh-NHS (Scheme 3a) was dried under vacuum.

The dried Rh-NHS dissolved in $10 \mathrm{~mL}$ DMSO where $0.4 \mathrm{~g}$ of the PEG-PPSu and $0.02 \mathrm{~mL}$ TEA were also added in proportional amounts. The solution was stirred overnight and then dialyzed for 2 days. The final product was collected by lyophilization (Scheme $3 b$ ).

\subsection{Functional materials characterization}

\subsubsection{Wide angle $X$-ray diffraction}

Wide Angle X-ray diffraction (WAXD) measurements of the samples were performed by an automated powder diffractometer Rigaku Mini Flex II with Bragg-Brentano 
Scheme 3 Schematic diagram of a Rhodamine's activation and b conjugation of activated Rhodamine to PEG-PPSu (a)

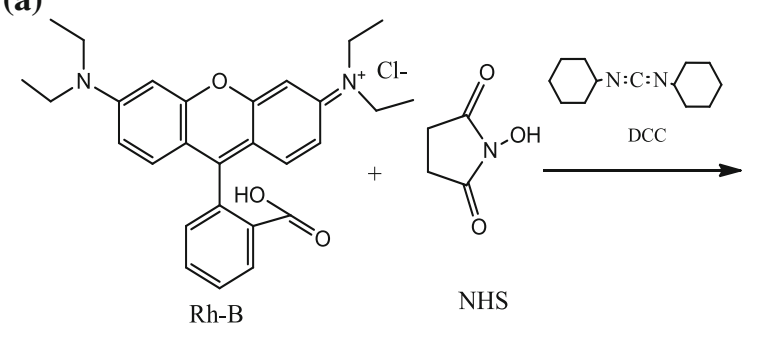<smiles>CCN(CC)c1ccc2c(-c3ccccc3C(=O)ON3C(=O)CCC3=O)c3ccc(=[N+](CC)CC)cc-3oc2c1</smiles>

(b) geometry $(\theta-2 \theta)$, using $\operatorname{CuK}_{\alpha}$ radiation $(\lambda=0.154 \mathrm{~nm})$ in the angle $2 \theta$ range from $5^{\circ}$ to $50^{\circ}$.

\subsubsection{Fourier-transform infrared spectroscopy}

FTIR spectra of the samples were taken with a FTIRspectrometer (model FTIR-2000, Perkin Elmer, Dresden, Germany) using $\mathrm{KBr}$ disks (thickness of $500 \mu \mathrm{m}$ ). The spectra were recorded from 4000 to $400 \mathrm{~cm}^{-1}$ at a resolution of $2 \mathrm{~cm}^{-1}$ (64 co-added scans).

\subsection{3 ${ }^{1}$ H-NMR spectroscopy}

${ }^{1} \mathrm{H}-\mathrm{NMR}$ spectra of polyesters were obtained with a Bruker spectrometer operating at a frequency of $400 \mathrm{MHz}$ for protons. Deuterated chloroform $\left(\mathrm{CDCl}_{3}\right)$ was used as solvent in order to prepare solutions of $5 \% \mathrm{w} / \mathrm{v}$. The number of scans was 10 and the sweep width was $6 \mathrm{kHz}$.

\subsubsection{Differential scanning calorimetry}

Differential scanning calorimetry (DSC) was performed on a Perkin-Elmer, Pyris Diamond differential scanning

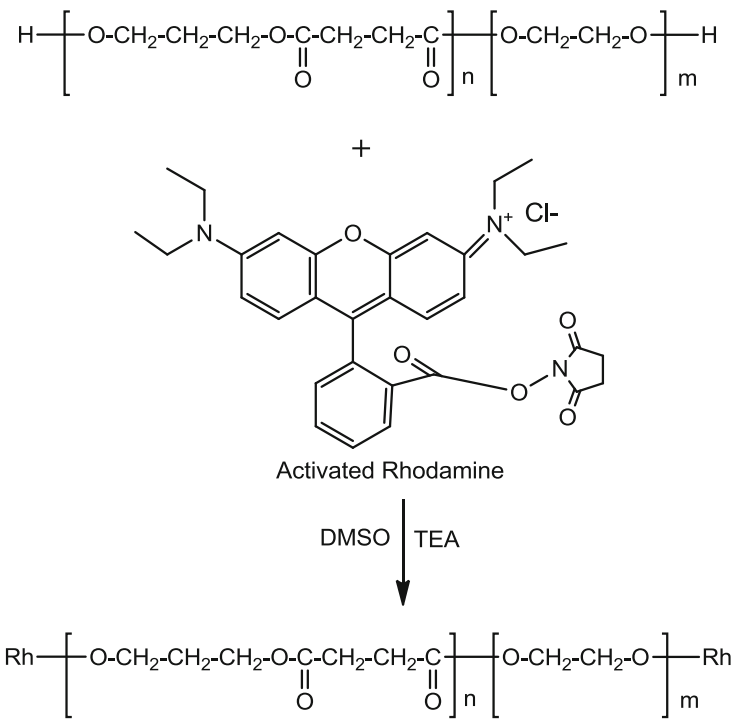

calorimeter. A Perkin Elmer Intracooler 2P cooling accessory was used. Samples of $5.0 \pm 0.1 \mathrm{mg}$ were sealed in aluminium pans and heated above the melting point of polyesters under nitrogen atmosphere at a heating rate $10^{\circ} \mathrm{C} / \mathrm{min}$.

\subsection{Preparation of IXA loaded polyester nanoparticles}

IXA nanoencapsulation was carried out with a modified water-oil-water (w/o/w) emulsification/solvent evaporation method. In brief, $5 \mathrm{mg}$ IXA were dissolved in $0.5 \mathrm{~mL}$ mixture of water with methanol $(35: 65 \mathrm{v} / \mathrm{v})$ and the solution was emulsified with probe sonication at $15 \mathrm{~W}$ for 2 min in a FA-PEG-PPSu-FA solution in dichloromethane, typically $50 \mathrm{mg}$ (45 mg of FA-PEG-PPSu$5 \mathrm{mg}$ Rh-PEG-PPSu) polymer in $3 \mathrm{~mL}$ solvent. This emulsion was transferred to an aqueous solution of PVA $(\mathrm{V}=9 \mathrm{~mL}, 0.66 \% \mathrm{w} / \mathrm{v} \mathrm{PVA})$ and the mixture was probe sonicated for $1 \mathrm{~min}$. The formed w/o/w emulsion was gently stirred at room temperature and organic solvents were allowed to be evaporated completely. The nanoparticles were purified by centrifugation $(9500 \mathrm{rpm}$ for $20 \mathrm{~min})$. The samples were reconstituted with deionized 
water. The suspension was filtered by a microfilter with pore size of $1.2 \mu \mathrm{m}$ in order to remove polymer aggregates possibly formed.

\subsection{Characterization of drug loaded nanoparticles}

\subsubsection{Nanoparticle yield, drug loading and entrapment efficiency}

For the determination of the drug loading content, $3 \mathrm{mg}$ of freeze-dried nanoparticles were dissolved in $50 \mu \mathrm{L} \mathrm{MeOH}$ and diluted to $40 \mathrm{~mL}$ ACN/10 mM ammonium acetate 70/ $30(\mathrm{v} / \mathrm{v})$. The concentration of IXA in this solution was measured by High Performance Liquid Chromatography system using a Shimadzu HPLC (model LC-20AD) system. The column used was a CNW Technologies Athena C18, $120 \mathrm{~A}, 5 \mu \mathrm{m}, 250 \mathrm{~mm} \times 4.6 \mathrm{~mm}$ with column temperature of $25^{\circ} \mathrm{C}$. The mobile phase consisted of ACN/10 mM ammonium acetate 70/30 (v/v) at a flow rate of $0.5 \mathrm{~mL} /$ min. Concentration determination was performed using an UV detector at $254 \mathrm{~nm}$ and was based on a previously created calibration curve. Nanoparticle yield, drug loading and drug entrapment efficiency were calculated using Eqs. (1)-(3), respectively:

Nanoparticles yield (\%)

$$
=\frac{\text { Weight of nanoparticles }}{\text { Weight of polymer and drug fed initially }} \times 100
$$

Drug loading content (\%)

$$
=\frac{\text { Weight of drug in nanoparticles }}{\text { Weight of nanoparticles }} \times 100
$$

Entrapment efficiency (\%)

$$
=\frac{\text { Weight of drug in nanoparticles }}{\text { Weight of drug fed initially }} \times 100
$$

\subsubsection{Morphology}

The morphology of the prepared nanoparticles was examined with a Scanning Electron Microscope (JEOL, JMS840). The samples were coated with carbon black to avoid charging under the electron beam. Operating conditions were: accelerating voltage $20 \mathrm{kV}$, probe current $45 \mathrm{nA}$, and counting time $60 \mathrm{~s}$.

\subsubsection{Particle size distribution by dynamic light scattering (DLS)}

Particle size distribution of the IXA/polyester nanoparticles was determined by dynamic light scattering (DLS) using a Zetasizer Nano instrument (Malvern Instruments, Nano ZS, ZEN3600, UK) operating with a $532 \mathrm{~nm}$ laser. A suitable amount of nanoparticles was dispersed in distilled water creating a total concentration $1 \%$ and was kept under agitation at $37{ }^{\circ} \mathrm{C}$ in a water bath. Particle size was measured at different time intervals after sample introduction into the dispersion medium. All measurements were performed in triplicates and the results were reported as mean diameter $\pm \mathrm{SD}$ (standard deviation).

\subsection{In vitro drug release}

For the in vitro release studies, a dissolution apparatus type DISTEK 2100B equipped with an autosampler using the paddle method (USP II method) was used. Each dissolution vessel was loaded with quantity of nanoparticles corresponding to $2 \mathrm{mg}$ of IXA. The test was performed at $37 \pm 1{ }^{\circ} \mathrm{C}$ with a rotation speed of $100 \mathrm{rpm}$. The dissolution medium was $500 \mathrm{~mL}$ of a solution simulating the inorganic composition of the body fluids (SBF) prepared according the Kokubo and Takadama procedure [23]. At predetermined time intervals, samples of $2 \mathrm{~mL}$ were withdrawn from the dissolution medium, filtered through $45 \mu \mathrm{m}$ UHMW polyethylene filters and assayed using an HPLC-UV method for the drug at $254 \mathrm{~nm}$. In order to investigate the release mechanism, the obtained release data were fitted to several release models, such as zero order, first order, Hixson Crowell, Higushi and KorsmeyerPeppas.

\subsection{In vitro cytotoxicity studies: cells and culture conditions}

HeLa Kyoto (HeLa K) and MCF7 cells were grown in Dulbecco's modified Eagle's medium (DMEM) supplemented with $10 \%$ FBS, $2 \mathrm{mM}$ L-glutamine, $100 \mathrm{U} / \mathrm{mL}$ penicillin and $100 \mu \mathrm{g} / \mathrm{mL}$ streptomycin (Invitrogen), at $37{ }^{\circ} \mathrm{C}$ with $5 \% \mathrm{CO}_{2}$ in a humidified incubator. Cell number was determined in duplicates using a haemocytometer. HeLa Kyoto and MCF7 cells were seeded in flat-bottomed 96-well plates (Sigma-Aldrich) at a density of 5000 and 8500 viable cells per well, respectively. Cells were incubated for $24 \mathrm{~h}$ to allow cell attachment. Cells were further incubated for $48 \mathrm{~h}$ with either PPSu-PEG or FA-PPSu-PEG nanoparticles at polymer concentrations ranging from 0.02 to $10 \mu \mathrm{g} / \mathrm{mL}$. After $48 \mathrm{~h}$, a cell proliferation assay was performed: cells were washed twice with $1 \mathrm{x}$ PBS followed by an additional 1-h incubation with $100 \mu \mathrm{L}$ of DMEM containing $10 \mu \mathrm{L} /$ well Premix WST-1 (Takara). Absorbance of the formazan product was measured at $440 \mathrm{~nm}$ using a microplate plate reader (Infinite M1000, Tecan), while the reference wavelength was measured at $660 \mathrm{~nm}$. Untreated cells were used as control for $100 \%$ viability, and wells with only the culture medium and the Premix were used as background control (blank). 


\subsection{Live cell microscopy}

For live cell microscopy, $3 \times 10^{4} \mathrm{HeLa}$ Kyoto cells were placed on Lab-Tek glass bottomed dishes 1 day before utilisation, and imaged on a customized Andor Revolution Spinning Disk Confocal System built around a stand (IX81; Olympus) with a $\times 20$ air objective and a digital camera (Andor Ixon +885$)$ (CIBIT Facility, MBG-DUTH) equipped with an incubator at $37{ }^{\circ} \mathrm{C}$. Prior to imaging, cells were washed twice with a $\mathrm{CO}_{2}$-independent medium, (04195374, Life technologies) supplemented with $10 \%$ FBS, $1 \%$ L-Glu, $100 \mathrm{U} / \mathrm{mL}$ penicillin and $100 \mu \mathrm{g} / \mathrm{mL}$ streptomycin, and then incubated in the same medium for imaging. Hoechst 33,342 at $1 \mu \mathrm{g} / \mathrm{mL}$ final concentration was used to visualise the cell nucleus. Rhodamine was covalently attached to the nanoparticles in order to visualize them. Images were acquired as $\mathrm{z}$ stacks, according to experimental needs. Autofocus was performed at each time point before capturing a $\mathrm{z}$-stack to ensure that the entire cell was captured. Image acquisition was performed in Andor IQ 2 software. Optical sections were recorded every $0.3 \mu \mathrm{M}$. Image intensity analysis for data sets were performed in ImageJ 1.44n (National Institute of Health, USA) software. All microscopy images presented here are 2D maximum intensity projections of z-stack images (ImageJ 1.44n National Institute of Health, USA).

\section{Results and discussion}

\subsection{Chemical structure and characterization of functional materials}

For the characterization of the synthesized materials and mainly to see if the proposed reactions are taking place ${ }^{1} \mathrm{H}$ NMR and FTIR spectroscopies were used and the recorded spectra of all materials are presented in Figs. 1 and 2, respectively. According to our previous study [9], the ${ }^{1} \mathrm{H}-$ NMR spectrum of neat PPSu presents a single peak at $2.63 \mathrm{ppm}$ which is attributed to the a (Fig. 1) methylene protons of succinic acid, a multiple peak between 1.9 and $2.02 \mathrm{ppm}$ corresponding to the d (See Fig. 1) protons of propanediol and a triple peak at 4.09-4.21 ppm attributed to the c (Fig. 1) protons $\left(-\mathrm{CH}_{2}-\mathrm{O}-\right.$ ) of propanediol. The ${ }^{1} \mathrm{H}-$ NMR spectrum of MAL-PEG-PPSu copolymer in addition exhibits a peak at $3.6 \mathrm{ppm}$ assigned to the methylene groups of PEG and a peak at 4.18-4.3 ppm ascribed to the methylene groups of ethyleneglycol [21]. FA-PEG-PPSu copolymer presents, in addition to the above mentioned peaks, two small peaks at 7.8 and $8.0 \mathrm{ppm}$ (See Fig. 1 and inset in Fig. 1) assigned to protons of FA [24].

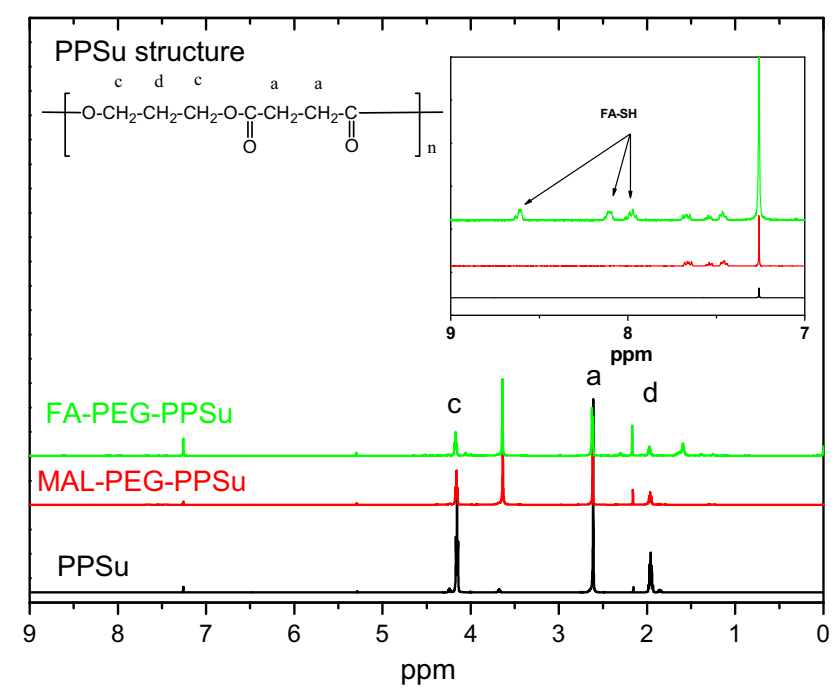

Fig. $1{ }^{1}$ H-NMR spectra of PPSu, MAL-PEG-PPSu and FA-PEGPPSu

Respectively, in FTIR spectrum (Fig. 2) of neat PPSu, a strong band at $1734-735 \mathrm{~cm}^{-1}$ of carbonyl groups $\mathrm{C}=\mathrm{O}$ and a broad band at $3433-3439 \mathrm{~cm}^{-1}$ assigned to $\mathrm{OH}$ groups can be observed. Furthermore, some other peaks at $1454-1474 \mathrm{~cm}^{-1} \quad(-\mathrm{CH}-)$ and at $1163-1167 \mathrm{~cm}^{-1}$ (C-O-C stretching) can be also seen [25]. MAL-PEG-PPSu spectrum includes the following peaks: the strong band at $1726 \mathrm{~cm}^{-1}$ assigned to the carbonyl groups of polyester and a broad band at $3500-3400 \mathrm{~cm}^{-1}$ corresponds to the hydroxyl groups of PEG conjugated to the polymer. Three small peaks that recorded at 1608,1686 and a $606 \mathrm{~cm}^{-1}$ in FA-PEGPPSu copolymer indicated the conjugation of modified FA into PEG-PPSu since these two peaks existed only in the neat modified FA [26]. Evidence of the existence of hydrogen bonding between FA and PEG provides the shifting in lower wavenumber of band at $1608 \mathrm{~cm}^{-1}$. FTIR spectroscopy as well as ${ }^{1} \mathrm{H}-\mathrm{NMR}$ confirm the successful preparation of the modified PPSu copolymers containing PEG and FA groups.

The successful conjugation of activated Rhodamine to PEG-PPSu was shown using FTIR spectroscopy. In Fig. $2 b$ the spectrum of Rhodamine $B$ is presented. At $2967 \mathrm{~cm}^{-1}$ the peak of the methylene groups of aromatic rings is observed while at $1766 \mathrm{~cm}^{-1}$ the absorbance of the carbonyl group is recorded. The shifting of the peak at $1731 \mathrm{~cm}^{-1}$ in the spectrum of Rh-MAL-PEG-PPsu material and the existence of a small peak at $1623 \mathrm{~cm}^{-1}$ $(\mathrm{C}=\mathrm{N}$ stretching $)$ indicate the successful conjugation of Rhodamine on the polymeric carrier. 

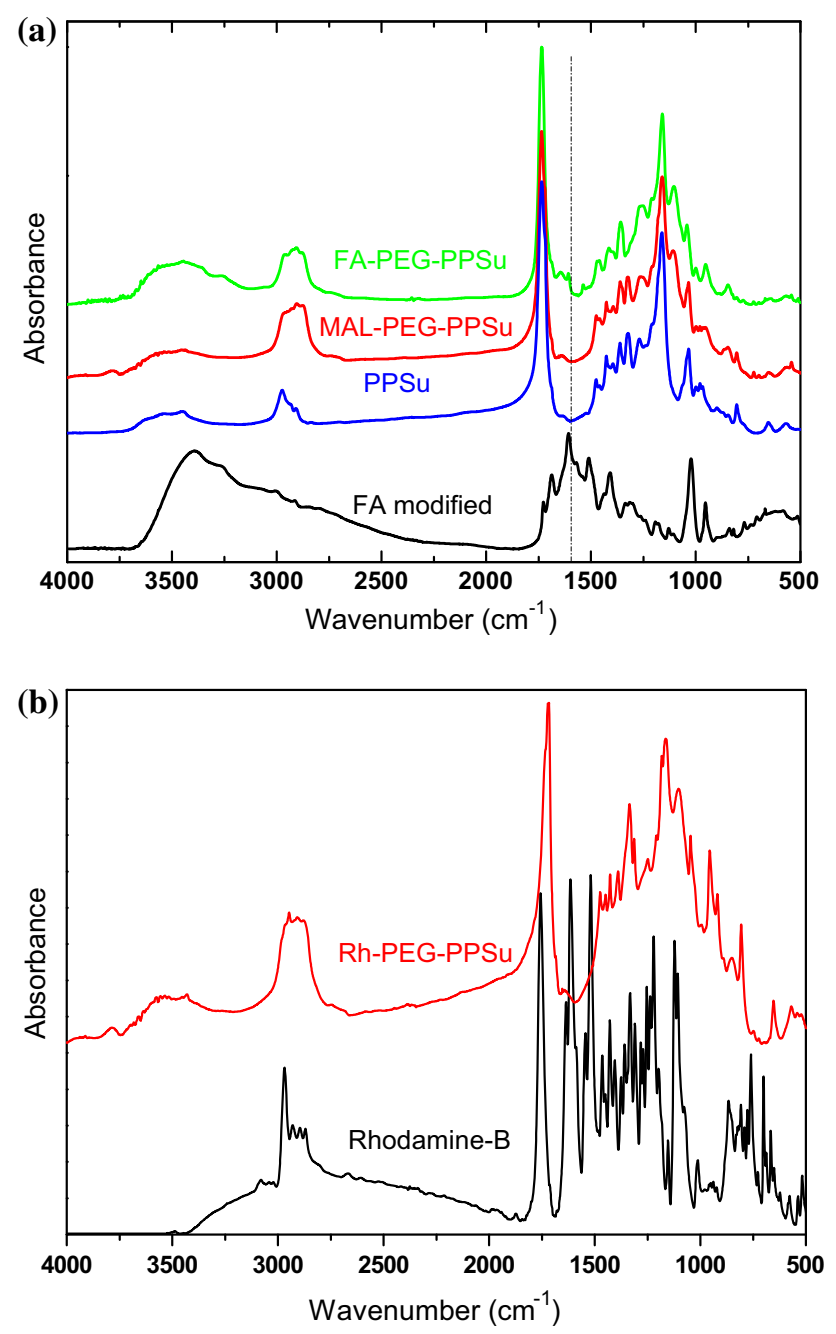

Fig. 2 FTIR spectra of a PPSu, modified FA, MAL-PEG-PPSu and FA-PEG-PPSu and b Rhodamine-B and Rh-PEG-PPSu

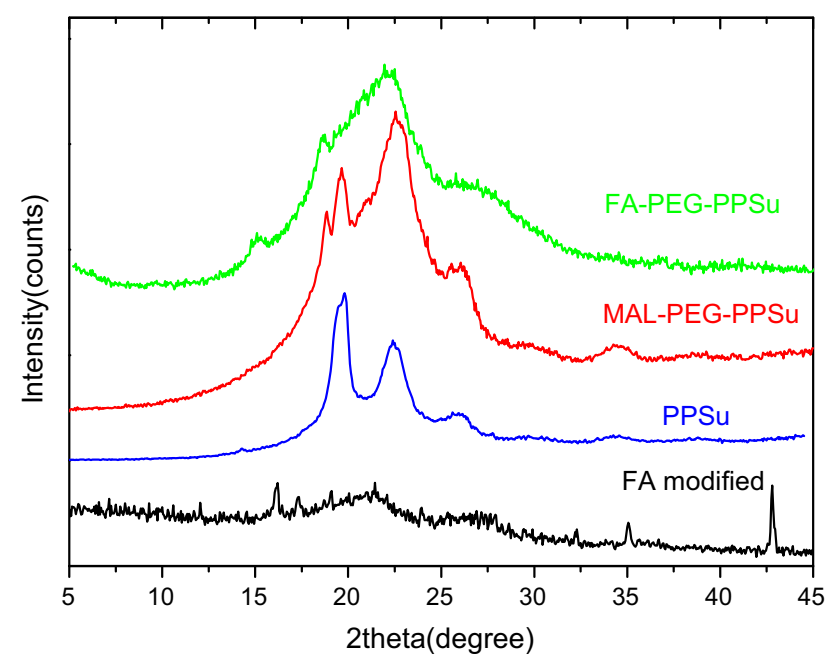

Fig. 3 X-ray diffraction (XRD) patterns of FA-NHS (FA modified), PPSu-neat, MAL-PEG-PPSu and FA-PEG-PPSu
The physical state of the synthesized functionalized PPSu copolymers has also been studied with XRD and DSC, since it is well known that crystallinity plays an important role in drug release from polymeric systems [27]. PPSu is a semicrystalline polyester with low melting point close to the human body temperature. In Fig. 3, the XRD patterns of neat PPSu, FA-PPSu, MAL-PEG-PPSu and FA-PEG-PPSu are illustrated. Neat PPSu presents characteristic crystalline peaks at $2 \theta=19.6^{\circ}, 22.49^{\circ}, 25.92^{\circ}$ and $34.45^{\circ}$. FA exhibits also weak peaks at $16^{\circ}, 35^{\circ}$ and $42^{\circ}$, confirming its crystalline nature. MAL-PEG-PPSu displays 4 main crystalline peaks at $19^{\circ}, 21^{\circ}, 22^{\circ}$ and $27^{\circ}$. These peaks appeared also in the diffractogram of FA-PEG-PPSu, too. However, in MAL-PEG-PPSu pattern there is also a small peak, which was recorded as shoulder, at $20.92^{\circ}$, corresponded to the addition of PEG into PPSu. After the addition of FA into MAL-PEG-PPSu, a more amorphous material was prepared (FA-PEGPPSu), since the peaks of PPSu are not so clearly visible. It appears that the addition of PEG and FA in PPSu chains modified its crystalline structure and copolymers with lower crystallinity were obtained.

Differential scanning calorimetry (DSC) was also used to investigate the physical structure of synthesized materials (See Fig. 4). Neat PPSu exhibited a melting point at $49{ }^{\circ} \mathrm{C}$ and a $\mathrm{T}_{\mathrm{g}}$ value at $-27.6{ }^{\circ} \mathrm{C}$, in accordance to our previous work [8]. The addition of MAL-PEG into PPSu reduced the melting point of PPSu to $35.6{ }^{\circ} \mathrm{C}$ due to cocrystallization with PEG, as was verified by the XRD studies, while a second melting point appeared at $47.4{ }^{\circ} \mathrm{C}$. The co-crystallization structural consequences became

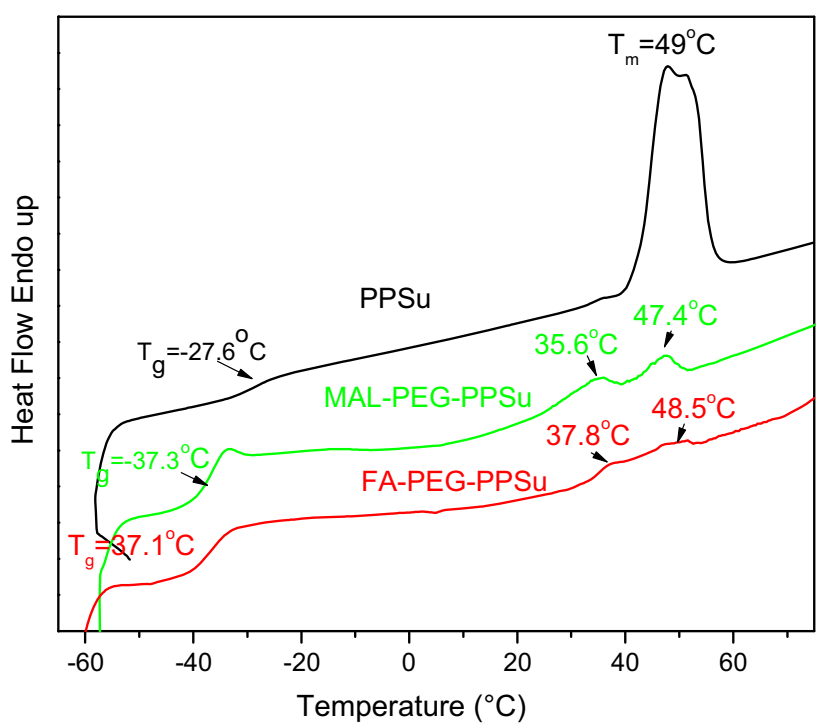

Fig. 4 Differential scanning calorimetry thermograms (DSC) of PPSu, MAL-PEG-PPSu, and FA-PEG-PPSu 
more clearly evident in the $\mathrm{T}_{\mathrm{g}}$ value, which is shifted to $-37.3{ }^{\circ} \mathrm{C}$ due to the plasticization effect of PEG, since neat PEG has a $\mathrm{T}_{\mathrm{g}}$ value near to $-60{ }^{\circ} \mathrm{C}$. The heat capacity at $\mathrm{T}_{\mathrm{g}}$ area in MAL-PEG-PPSu sample has been increased while the heat of fusion of melting point has been reduced, compared with neat PPSu, which is an indication that MAL-PEG-PPSu is more amorphous than PPSu. The $\mathrm{T}_{\mathrm{g}}$ temperature of FA-PEG-PPSu appeared at $-37.1{ }^{\circ} \mathrm{C}$, almost identical to that of MAL-PEG-PPSu. Two meting points were also recorded at 37.8 and $48.5{ }^{\circ} \mathrm{C}$, but the respective peaks were smaller than those corresponding to MAL-PEG-PPSu. This confirms that FA-PEG-PPSu is more amorphous than neat PPSu and its MAL-PEG-PPSu copolymer, in accordance to the XRD results (See Fig. 3).

\subsection{Characterization of functionalized nanoparticles}

The FA-modified copolymers were used to prepare IXAloaded nanoparticles. The prepared nanoparticles were initially characterized using SEM and Fig. 5 presents SEM micrograph of FA-PEG-PPSu nanoparticles of IXA. It is clear that individual particles with spherical shape were obtained. Dynamic light scattering (DLS) was used to characterize the size characteristics of the nanoparticles. Size is important for efficient tumor localization of nanoparticles after intravenous administration, with nanoparticles with size in the range of 20-200 nm accumulating preferentially at tumors due to the EPR phenomenon [20, 21]. According to DLS measurements (See Fig. 6), the size of nanoparticles ranged between 40 and $700 \mathrm{~nm}$, with a mean particle size of $195 \mathrm{~nm}$ while the majority of the NPS present the favorable size of 100-200 $\mathrm{nm}$. Therefore, we can suggest the folate-NPS are

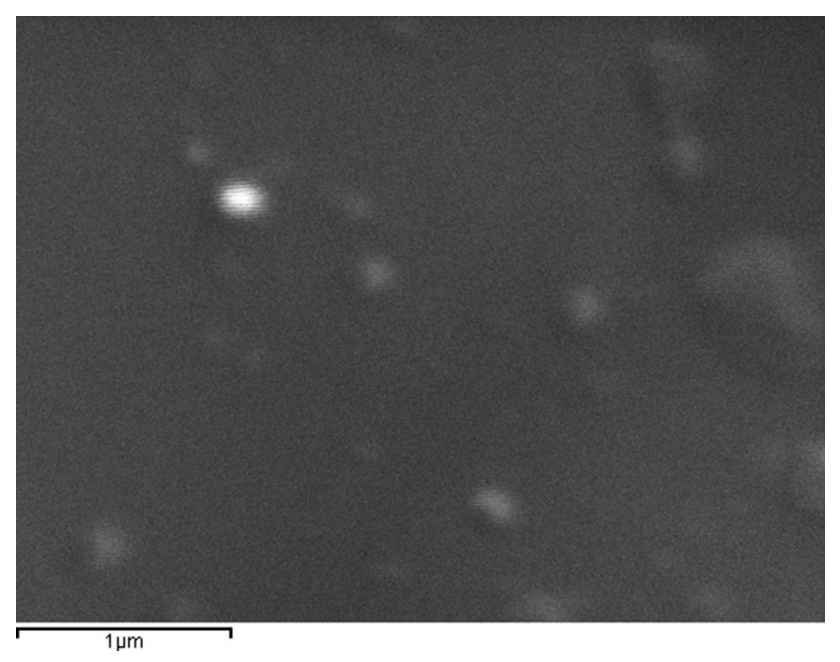

Fig. 5 SEM photograph of IXA-loaded FA-PEG-PPSu nanoparticles

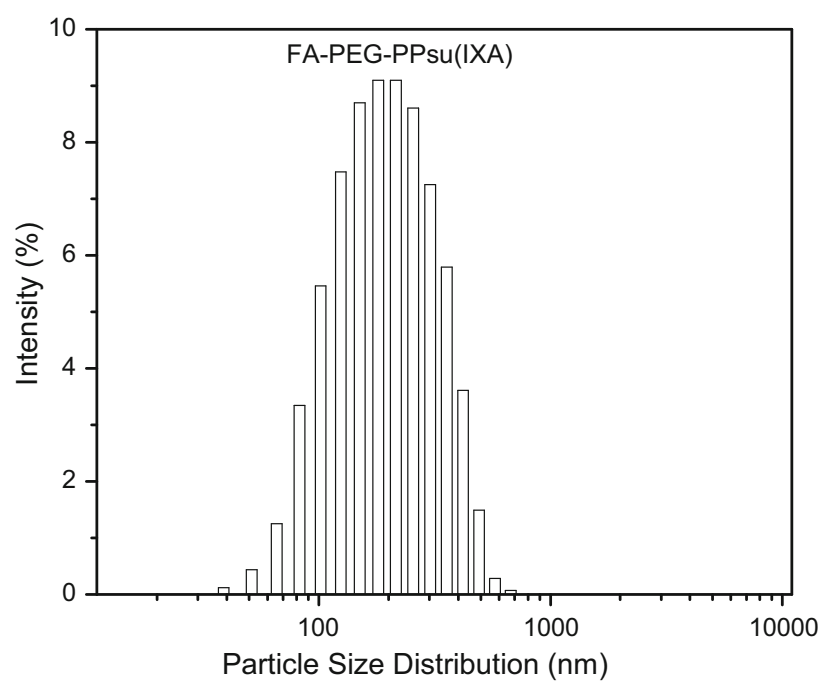

Fig. 6 Particle size distribution of IXA-loaded FA-PEG-PPSu nanoparticles based on DLS

suitable for their potential use as targetable nanocarriers of IXA [28-30]. In the literature, the definition of nanoparticles is not clear. However, according to several works, the researchers define NPs even they have 500 or $700 \mathrm{~nm}$ size [31].

Drug loading in nanoparticles can be affected by various factors, such as polymer molecular weight, crystallinity and ratio of hydrophilic segments in the macromolecular chains [22]. Table 1 summarizes the nanoparticle yield, drug loading and entrapment efficiency of FA-PEG-PPSu nanoparticles. Satisfactory IXA (\%) loading and entrapment efficiency were obtained with the modified w/o/w emulsification and solvent evaporation technique applied to prepare the nanoparticles.

In order to reveal if there any interactions between IXA (Fig. 7a) and polymer matrix, all prepared nanoparticles were studied by FTIR spectroscopy and were compared with IXA and the Folate-polymer spectra. As it can be seen in Fig. 7b, the characteristic peaks of IXA are recorded at 3400 and $2982 \mathrm{~cm}^{-1}$ corresponding to its hydroxyl group and the secondary amino group, respectively. The spectrum of nanoparticles loaded with IXA is similar to that of unloaded FA-PEG-PPSu nanoparticles. So, it can be argued that there are no interactions between drug and polymer carrier.

$\mathrm{X}$-Ray diffraction studies were performed in order to study the physical form of the drug in the prepared nanoparticles (Fig. 8). The diffractogramm of neat IXA exhibits some sharp diffraction peaks, with the most characteristic of them appearing at $15^{\circ}-25^{\circ}$. As it was mentioned above, FA-PEG-PPSu presents a broad peak, indicating a mainly amorphous structure of the synthesized 
Table 1 Nanoparticle yield, drug loading and entrapment efficiency of IXA-loaded FA-PEG-PPSu nanoparticles

\begin{tabular}{llll}
\hline & Nanoparticle yield $(\%)$ & Drug loading $(\%)$ & Entrapment efficiency $(\%)$ \\
\hline IXA loaded FA-PEG-PPSu & 39.09 & 3.53 & 38.80 \\
\hline
\end{tabular}

(a)

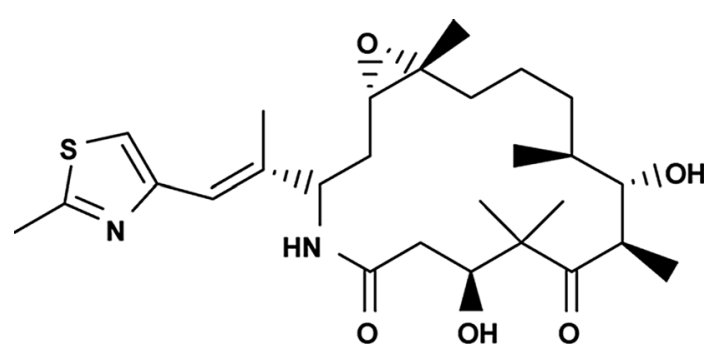

(b)

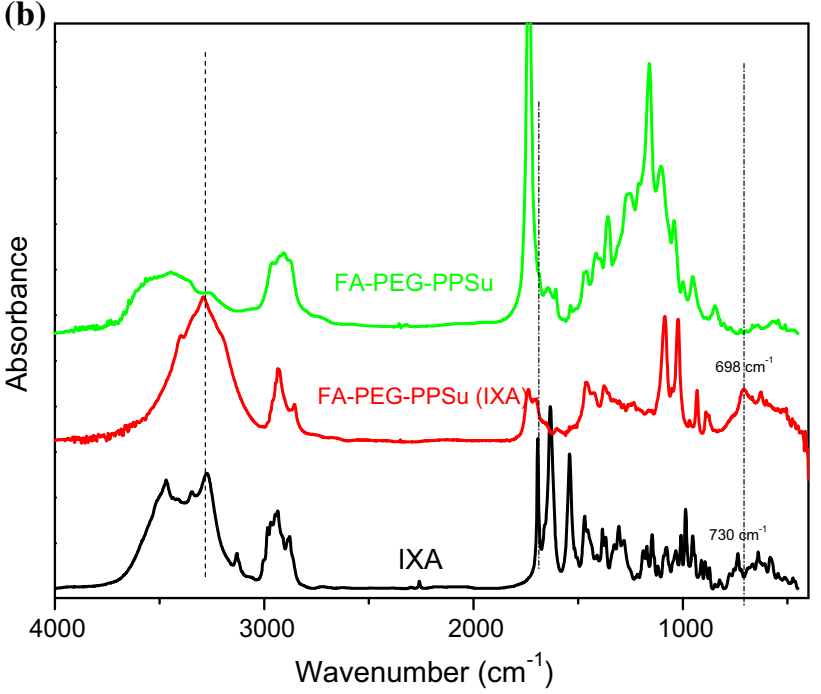

Fig. 7 a Structure of ixabepilone and b FTIR spectra of IXA, IXAloaded FA-PEG-PPSu nanoparticles, and FA-PEG-PPSu nanoparticles

material. In the case of loaded nanoparticles with IXA, the diffractogamm is similar to that of blank nanoparticles. However, the characteristic peaks of neat IXA were not recorded, indicating the dispersion of IXA in amorphous form inside the nanoparticles.

\subsection{In vitro drug release}

The drug release from nanoparticulate systems consisting of biodegradable polymers can be influenced by different parameters, such as crystallinity, glass transition temperature, melting point, molecular weight, drug entrapment efficiency to the polymer, nanoparticles' size and drug's hydrophilicity [23, 32-34]. In Fig. 9, the in vitro release

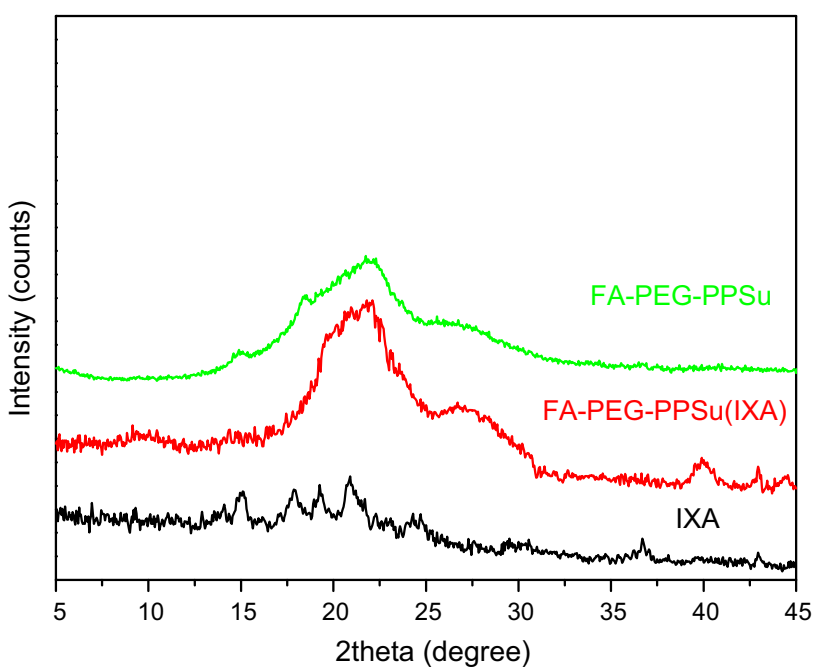

Fig. 8 XRD diffractogram of FA-PEG-PPSu nanoparticles, IXAloaded FA-PEG-PPSu nanoparticles and IXA

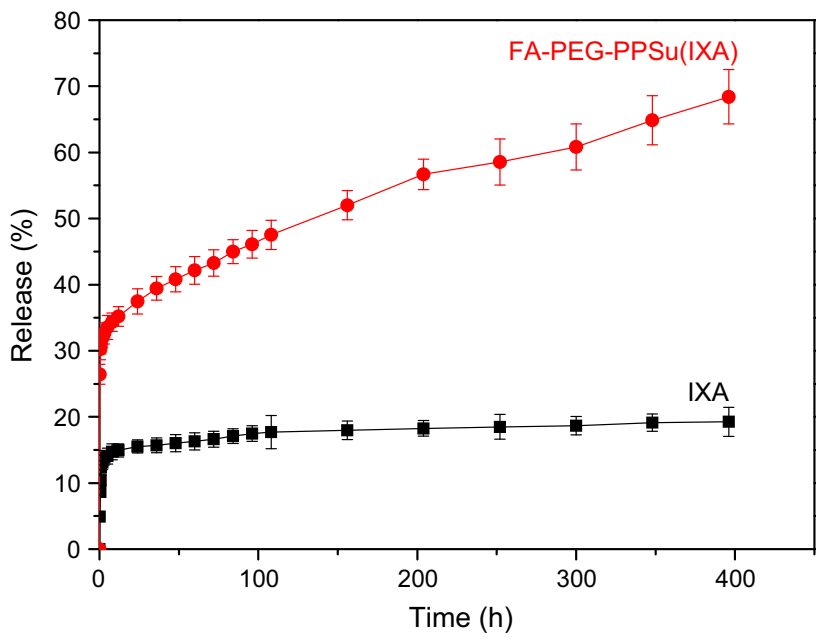

Fig. 9 Release profile of neat IXA and IXA encapsulated in FAPEG-PPSu nanoparticles

profiles of non-encapsulated IXA and IXA-loaded nanoparticles are shown. IXA is poorly soluble drug according to the literature [35]. About $10 \%$ percentage of free IXA had been dissolved during the first $5 \mathrm{~h}$. Then, very slow dissolution was observed indicating the inability of the chosen model drug to fully be dissolved in body 


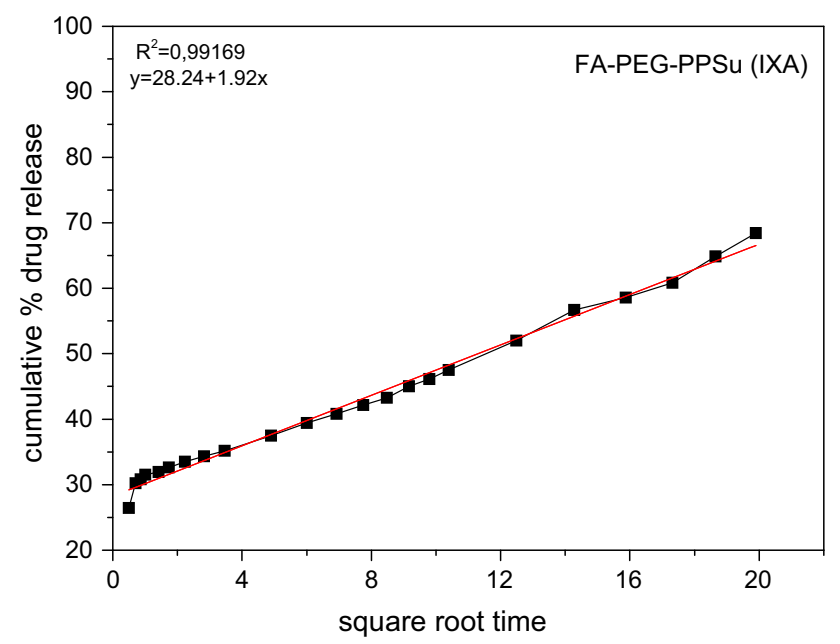

Fig. 10 Fitting the release profile obtained with the nanoparticles to Higuchi release model

fluids. However, the initial, relatively fast dissolution could be attributed to the rapid dissolution of IXA particles with very small diameter. As far of our knowledge, there are no reports studying NPs loaded with IXA, consisting of biodegradable polymer such as PPSu, PLA or PCL. However, PPSu attached to hydrophilic segments of PEG has been studied for several model drugs [17]. Vassiliou et al., showed that when a hydrophobic drug is entrapped in such polyesters higher release rates are verified as well as that the hydrophobic drug was mainly entrapped in hydrophobic segments [17]. Taxol a known anti-cancer drug was successfully encapsulated in magnetic core-shell NPs of PPsu in which case observed a biphasic pattern- a high release rate followed by slow dissolution [36]. In our case of nanoparticles, a biphasic pattern can also be identified. This behaviour is similar for polymeric nanoparticles [27, 33]. The burst release of around $35 \%$ of IXA content was observed during the first $2 \mathrm{~h}$, which was followed by a sustained release. Burst release phenomenon according to the literature does not have a clear mechanism however can be controlled by the manufacturing procedure [37]. The initial fast release from the nanoparticles could be attributed to the rapid dissolution of drug located on/close to nanoparticles' surface $[38,39]$. The higher dissolution rate of encapsulated IXA compared to free (crystalline) IXA can be attributed to the mainly amorphous state of IXA entrapped into the polymeric matrix, as indicated by XRD studies (See Fig. 8). IXA is mainly encapsulated in the amorphous form in the nanoparticles and it is well known that amorphous drugs have higher solubility compared with their crystalline counterparts [33].

The in vitro release profile of IXA from the FA-PEGPPSu nanoparticles was analyzed by various kinetic models. The kinetic models used were zero order, first order, Higuchi and Korsemeyer-Peppas equation [37]. Release kinetics was found to fit the Higuchi model best (See Fig. 10) and thus the release mechanism may be considered to be drug diffusion.

Additionally, in the prepared NPs it is believed that a high content of the drug is located near the hydrophilic part of FA-PEG. After these early stages, the drug from the hydrophobic part is diffused from the hydrophobic part indicating the slower release.

\subsection{In vitro cytotoxicity and cellular uptake studies}

The human cervical cancer cell line HeLa Kyoto (HeLa K) and the human breast cancer cell line MCF7 were used to test the cytotoxicity of PPSu-PEG and FA-PPSu-PEG nanoparticles (NPs) without IXA. The NPs were weighed, suspended in PBS and added in HeLa K and MCF7 cells. Figure 11a shows the viability of HeLa K and MCF7 cells after $48 \mathrm{~h}$ of cell culture with either PPSu-PEG or FAPPSu-PEG in polymer concentration ranging from 0.02 to $10 \mu \mathrm{g} / \mathrm{mL}$. No significant cytotoxic activity was found for the drug-free NPs at all tested concentrations. Moreover, the addition of folic acid (FA) on the polymer molecules did not significantly affect cell viability, since $97.2 \% \pm 0.06 \%$ of HeLa K cells and $87.73 \% \pm 0.01 \%$ of MCF7 cells remained viable after $48 \mathrm{~h}$ of incubation with the nanoparticles. As a conclusion, the two different NPs tested in the two cancer cell lines did not result to significant loss of cell viability and thus can be considered to be safe and non-toxic.

In order to confirm the cellular uptake of the FA-PPSuPEG nanoparticles after being modified by the tumor cellspecific targeting ligand folic acid, HeLa cells cell were used, which are folic acid receptor positive. In order to visualize the nanoparticles, Rhodamine (Rho) was covalently attached to them and HeLa cells were incubated in the presence of PPSu-PEG-Rho nanoparticles and their cell entry was imaged live using a confocal microscope (See Fig. 11b). Cell entry started at early time points, achieving a maximum at $5 \mathrm{~h}$. The results confirm the ability of FA-PPSu-PEG nanoparticles to enter folic-acid receptor positive cells (HeLa). 
(a)

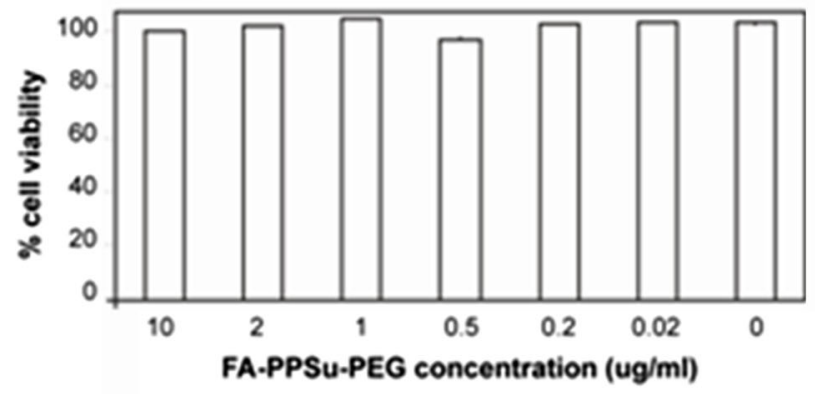

FA-PPSU.PEG in MCF7

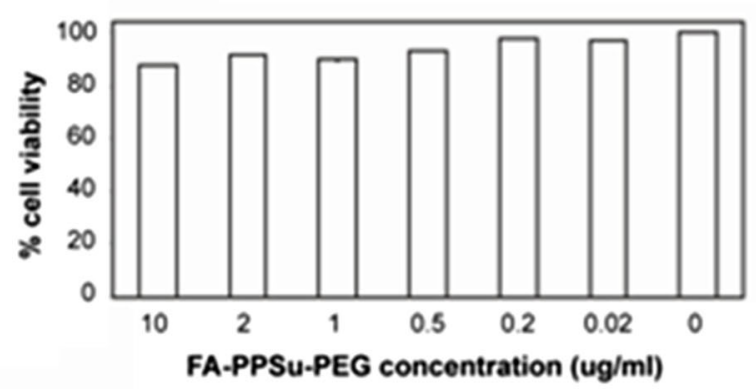

PPSU-PEG in HeLa K

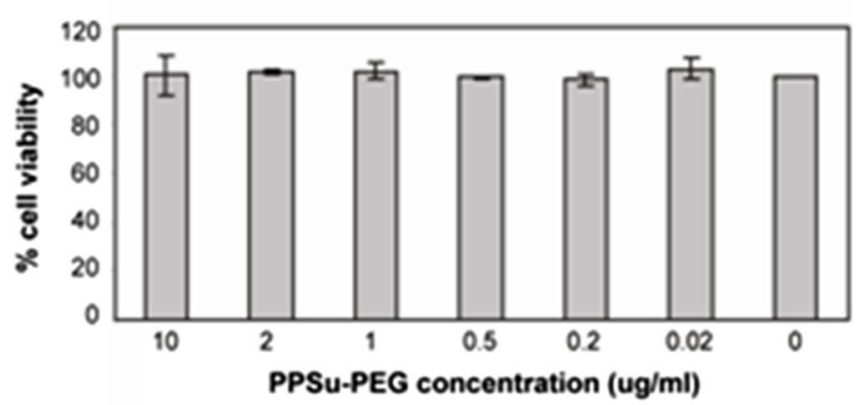

PPSU-PEG in MCF7

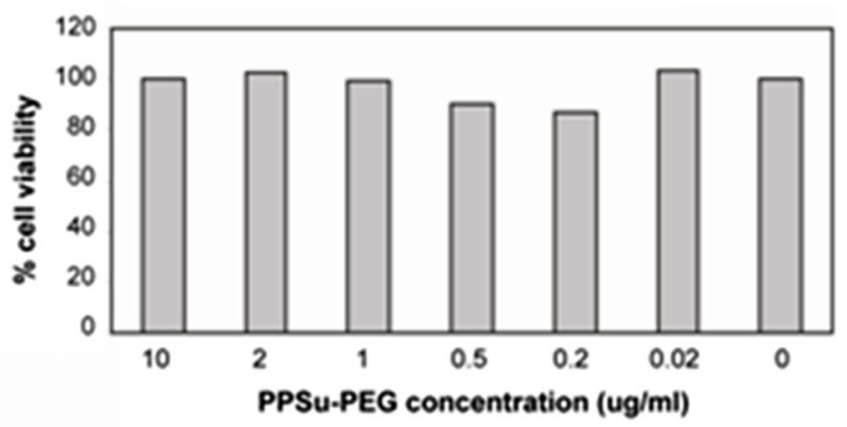

(b)

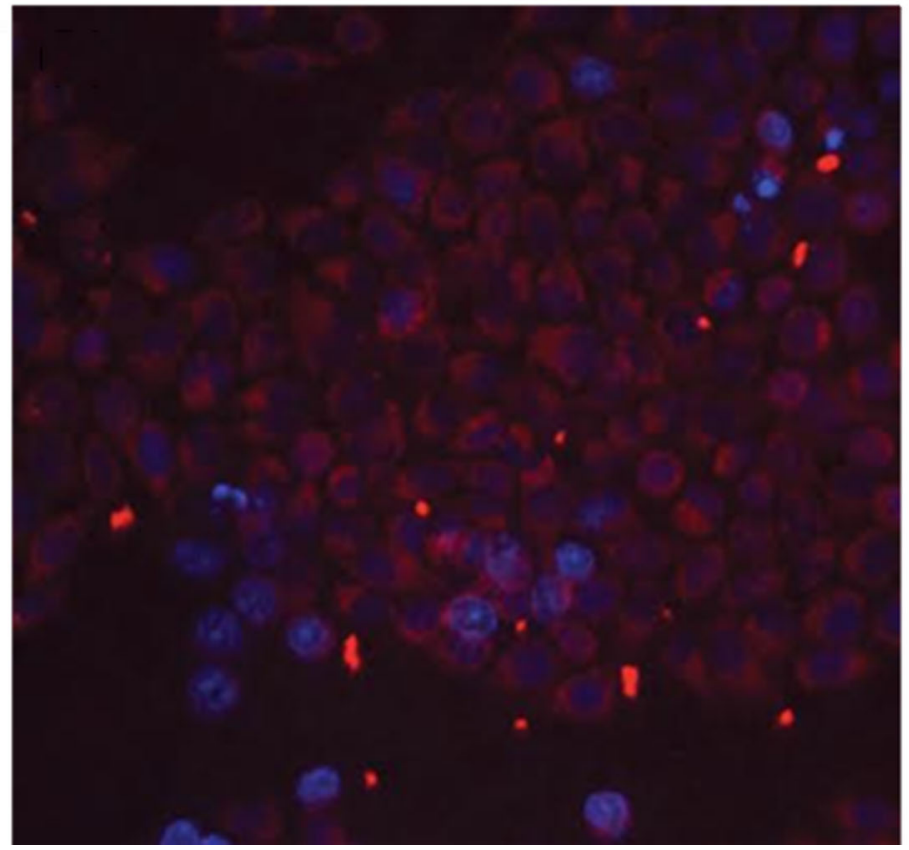

Fig. 11 a Viability of HeLa K and MCF7 cells after 48 h incubation with PPSu-PEG and FA-PPSu-PEG nanoparticles. Graphs are the mean of 3 independent experiments \pm SD. b Representative image showing the cellular uptake of the FA-PPSu-PEG-Rho nanoparticles in HeLa Kyoto cells, $5 \mathrm{~h}$ after their addition to the cell medium. Cell nuclei were stained with Hoechst 33,342 


\section{Conclusion}

A novel FA-functionalized PEG-PPSu copolymer was successfully synthesized and fully characterized. In vitro cytotoxicity studies indicated that FA-PEG-PPSu is a cytocompatible material that could safely be used for the development of targetable nanoparticulate drug carriers. IXA-loaded nanoparticles of FA-PEG-PPSu, were prepared in a satisfactory yield and with a satisfactory IXA loading efficiency. The nanoparticles exhibited sustained drug release profile in simulating body fluid. Moreover, the nanoparticles were able to enter human breast cancer cells that express the FA receptor. The results obtained justify further investigation of the suitability of these nanoparticles to be utilized as targetable IXA nanocarriers in breast cancer chemotherapy.

Acknowledgments The authors wish to acknowledge co-funding of this research by European Union-European Regional Development Fund and Greek Ministry of Education/EYDE-ETAK through program ESPA 2007-2013/EPAN II/Action "SYNERGASIA" (09SYN41-659).

\section{References}

1. European Medicines Agency, Evaluation of Medicines for Human Use, Ixempra Withdrawal Assessment ReportEUROPA-EU website PDF (2009). http://www.ema.europa.eu/ docs/en_GB/document_library/Application_withdrawal_assess ment_report/2010/01/WC500062429.pdf.

2. Denduluri N, Swain S. Ixabepilone: clinical role in metastatic breast cancer. Clin Breast Canc. 2011;11(3):139-45.

3. Fornier MN. Ixabepilone first in a new class of antineoplastic agents: the natural epothilones and their analogues. Clin Breast Canc. 2007;7(10):757-63.

4. Xu XS, Zeng J, Mylott W, Arnold M, Waltrip J, Iacono L, Mariannino T, Stouffer B. Liquid chromatography and tandem mass spectrometry for the quantitative determination of ixabepilone (BMS-247550, IxempraTM) in human plasma: method validation, overcoming curve splitting issues and eliminating chromatographic interferences from degradants. J Chromatogr B. 2010;878(5-6):525-37.

5. Magadala P, LE Vlerken, Shahiwala A, Amiji MM. Multifunctional polymeric nanosystems for tumor-targeted delivery. In: Torchilin VP, editor. Multifunctional pharmaceutical nanocarriers, vol. 4. New York: Springer; 2008. p. 33-64.

6. Kumagai Y, Doi Y. Enzymatic degradation and morphologies of binary blends of microbial poly(3-hydroxybutyrate) with poly(ecaprolactone), poly(1,4-butylene adipate and poly(vinyl acetate). Polym Degrad Stab. 1992;36:241-8.

7. Bikiaris D, Karavelidis V, Karavas E. Effectiveness of various drug carriers in controlled release formulations of raloxifene $\mathrm{HCl}$ prepared by melt mixing. Curr Drug Delivery. 2009;6(5):425-36.

8. Bikiaris DN, Papageorgiou GZ, Papadimitriou SA, Karavas E, Avgoustakis K. Novel biodegradable polyester poly(propylene succinate): synthesis and application in the preparation of solid dispersions and nanoparticles of a water-soluble drug. AAPS Pharm Sci Tech. 2009;10(1):138-46.
9. Bikiaris DN, Papageorgiou GZ, Achilias DS. Synthesis and comparative biodegradability studies of three poly(alkylene succinate)s. Polym Degrad Stab. 2006;91(1):31-43.

10. Papageorgiou GZ, Bikiaris DN. Crystallization and melting behavior of three biodegradable poly(alkylene succinates). A comparative study. Polymer. 2005;46:12081-92.

11. Chan P, Kurisawa M, Chung JE, Yang YY. Synthesis and characterization of chitosan-g-poly(ethylene glycol)-folate as a nonviral carrier for tumor-targeted gene delivery. Biomaterials. 2007;28(3):540-9.

12. Couvreur P, Vauthier C. Nanotechnology: intelligent design to treat complex disease. Pharm Res. 2006;23(7):1417-50.

13. Du ZX, Xu JT, Yang Y, Fan ZQ. Synthesis and characterization of Poly(e-caprolactone)-poly(ethylene glycol) block copolymers prepared by a salicylaldimine-aluminum complex. J Appl Polym Sci. 2007;105(2):771-6.

14. Duncan R. Polymer conjugates as anticancer nanomedicines. Nat Rev Cancer. 2006;6:688-701.

15. Kyriakopoulou S, Mattheolabakis G, Papadimitriou S, Karavas E, Bikiaris D, Avgoustakis K. PPSu-PEG copolymers and their application in the preparation of cisplatin-loaded nanoparticles. Curr Nanosc. 2011;7:503-9.

16. Tong R, Cheng J. Anticancer polymeric nanomedicines. Polym Rev. 2007;47:345-81.

17. Vassiliou AA, Papadimitriou SA, Bikiaris DN, Mattheolabakis G, Avgoustakis K. Facile synthesis of polyester-PEG triblock copolymers and preparation of amphiphilic nanoparticles as drug carriers. J Control Release. 2010;148:388-95.

18. Vlerken LE, Amiji MM. Multi-functional polymeric nanoparticles for tumour-targeted drug delivery. Exp Opin Drug Deliv. 2006;3(2):205-16.

19. Choi CH, Alabi CA, Webster P, Davis ME. Mechanism of active targeting in solid tumors with transferrin-containing gold nanoparticles. Proc Natl Acad Sci USA. 2010;107:1235-40.

20. Parveen S, Misra R, Sahoo SK. Nanoparticles: a boon to drug delivery, therapeutics, diagnostics and imaging. Nanomed Nanotech Biol Med. 2012;8(2):147-66.

21. Wang S, Luo Y, Zeng S, Luo C, Yang L, Liang Z, Wang Y. Dodecanol-poly(d, L-lactic acid)-b-poly (ethylene glycol)-folate (Dol-PLA-PEG-FA) nanoparticles: evaluation of cell cytotoxicity and selecting capability in vitro. Colloid Surf B. 2013;102:130-5.

22. Cho K, Wang X, Nie S, Hu X, Yan L, Xiao H, Li X, Jing X. Application of Microwave-Assisted Click Chemistry in the Preparation of Functionalized Copolymers for Drug Conjugation. J Appl Chem. 2013;127(5):3365-73.

23. Kokubo T, Takadama H. How useful is SBF in predicting in vivo bone bioactivity? Biomaterials. 2006;27(15):2907-15.

24. Zhu J, Zhou Z, Yang C, Kong D, Wan Y, Wang Z. Folateconjugated amphiphilic star-shaped block copolymers as targeted nanocarriers. J Biomed Mat Res. A. 2011;97(4):498-508.

25. Gupta MC. Atomic and molecular spectroscopy. New Delhi: S. Chand Co; 2003. p. 235-9.

26. Anderson KA, Stevenson BR, Rogers J. Folic acid-PEO-labeled liposomes to improve gastrointestinal absorption of encapsulated agents. J Control Rel. 1999;60(2-3):189-98.

27. Papadimitriou S, Bikiaris D. Novel self-assembled core-shell nanoparticles based on crystalline amorphous moieties of aliphatic copolyesters for efficient controlled drug release. J Control Rel. 2009;138(2):177-84.

28. Cho K, Wang X, Nie S, Chen Z, Shin DM. Therapeutic Nanoparticles for Drug Delivery in Cancer. Clin Cancer Res. 2008;14(5):1310-6.

29. Chen Z, Shin DM. Therapeutic Nanoparticles for Drug Delivery in Cancer. Clin Cancer Res. 2008;14(5):1310-6. 
30. Moghimi SM, Hunter AC. MurrayJC. Long-circulating and target-specific nanoparticles: theory to practice. Pharmacol Rev. 2001;53:283-318.

31. Moreno-Vega A-I, Gómez-Quintero T, Nuñez-Anita R-E, Acosta-Torres L-S, Castaño V. Polymeric and ceramic nanoparticles in biomedical applications. J Nanotech. 2012;2012:1-10.

32. Gref R, Minamitake Y, Peracchia MT, Trebetskoy VS, Torchilin VP, Langer R. Biodegradable long-circulating polymeric nanospheres. Science. 1994;263(5153):1600-3.

33. Karavelidis V, Karavas E, Giliopoulos D, Papadimitriou S, Bikiaris D. Evaluating the effects of crystallinity of new biocompatible polyester nanocarriers on drug release behaviour. Int $\mathbf{J}$ Nanomed. 2011;6:3021-32.

34. Zhang L, Hu Y, Jiang X, Yang C, Lu W, Yang YH. Camptothecin derivative-loaded poly(caprolactone-co-lactide)-b-PEG-b-poly(caprolactoneco-lactide) nanoparticles and their biodistribution in mice. J Control Rel. 2004;96(1):135-48.

35. Cobham MV, Donovan D. Ixabepilone: a new treatment option for the management of taxane-resistant metastatic breast cancer. Canc Manag Res. 2009;1:69-77.
36. Filippousi M, Papadimitriou SA, Bikiaris DN, Pavlidou EN, Angelakeris M, Zamboulis D, Tian H, Van Tendeloo G. Novel core-shell magnetic nanoparticles for Taxol encapsulation in biodegradable and biocompatible block copolymers: preparation, characterization and release properties. Int $\mathrm{J}$ Pharm. 2013;448:221-30.

37. Huang X, Brazel C. On the importance and mechanisms of burst release in matrix-controlled drug delivery systems. J Contr Rel. 2001;73:121-36.

38. Ge H, Hu Y, Jiang X, Cheng D, Yuan Y, Bi H, Yang C. Preparation, characterization and drug release behaviours of drug nimodipine-loaded poly(caprolactone)-poly(ethylene oxide)poly(caprolactone) amphiphilic triblock copolymer micelles. J Pharmac Sci. 2002;91(6):1463-73.

39. Costa P, Lobo JMS. Modeling and comparison of dissolution profiles. Eur J Pharm Sci. 2001;13(2):123-33. 